Article

\title{
Surface Acting and Job-Related Affective Wellbeing: Preventing Resource Loss Spiral and Resource Loss Cycle for Sustainable Workplaces
}

\author{
Seongwook $\mathrm{Ha}^{(\mathbb{D})}$ \\ Division of Management, Hansung University, 116 Samseongyo-ro 16gil, Seongbuk-gu, Seoul 02876, Korea; \\ hass@hansung.ac.kr; Tel.: +82-2-760-4462
}

Received: 12 February 2018; Accepted: 5 April 2018; Published: 6 April 2018

check for updates

\begin{abstract}
This study empirically examines the synergistic negative effect of two kinds of job demand on job-related affective wellbeing (JAW) and the accelerating effects of cynicism in the negative relationships between job demands and JAW using a sample of 299 employees in the Chinese banking industry. Job demands include quantitative role overload and surface acting to represent the quantitative and qualitative aspects of job demands. Cynicism is introduced as a state where one's energy resource is lost. The results of this study show that surface acting has a negative relationship with JAW, but quantitative role overload has no relationship with JAW. High levels of quantitative role overload exacerbate the negative relationship between surface acting and JAW. Cynicism also exacerbates the negative relationship between surface acting and JAW but does not have any moderating effect in the relationship between quantitative role overload and JAW. These results are consistent with the relationships predicted by resource loss spiral and resource loss cycle. The resource loss spiral means that resource loss, caused by handling with a quantitative role overload, lessens the employee's ability to cope with surface acting. The resource loss cycle represents a vicious circle that amplifies the resource loss caused by surface acting. Surface acting reduces the level of one's resources. Furthermore, surface acting reduces JAW and resources more strongly when an individual has low levels of previous energy resources than it reduces JAW and resources when he or she has high levels of previous energy resources.
\end{abstract}

Keywords: job-related affective wellbeing; quantitative role overload; surface acting; cynicism; resource loss spiral; resource loss cycle

\section{Introduction}

People's resources are key concepts that explain their stress resistance and wellbeing [1,2]. Resources are broadly defined as "those objects, personal characteristics, conditions, or energies that are valued in their own right or that are valued because they act as conduits to the achievement or the protection of valued resources (p. 311)" [1]. Wellbeing and health are influenced by resource change in the face of stressful challenges $[1,2]$. Conservation of resources (COR) theory assumes that an individual strives to obtain, retain, and protect resources, and that stress occurs, and wellbeing is undermined when the individual is threatened with resource loss or loses resources or fails to gain resources following the investment of resources $[1,3]$.

According to COR theory assumptions, resource loss has stronger impacts on an individual's stress resistance and wellbeing than resource gain. Resource loss, which is defined as approaching "critical survival level (p. 131)" [4] or "precipice (p. 318)" [5], is scary as it might increase the likelihood that an individual is in a state of irreversible ultimate consequences, especially when the resource levels of their resource reservoir is low. Furthermore, resource gain has more meaningful value from its 
association to resource loss than it has to its own value because the need to maintain resource reservoir to combat stress is urgent in the face of previous resource loss $[3,4]$.

However, resource loss has rarely been examined empirically, but there are some exceptions. Wells et al. [3] showed that initial resource loss amplified the positive relationship between further resource loss and psychological distress. This means that resource loss leads to further a "resource loss cycle" that "intensifies in momentum as each loss makes the system more vulnerable and less likely to meet ongoing demands of stress or day-to-day adaptation (p. 1173)". They also showed that resource gain lessened the positive relationship between resource loss and psychological distress, meaning that resource gain and the accompanying emotions become more important in the face of previous resource loss. Van Woerkom et al. [6] showed that employee absenteeism was exacerbated when exposed to a combination of different types of job demands such as workload and emotional demands, which means that resource loss caused by handling one type of job demand lessens an employee's ability to cope with another type of job demand, known as the "resource loss spiral (p. 141)".

Employee sustainability in the workplace may be undermined when an employee's resource loss accelerates under a resource loss cycle and/or resource loss spiral. An individual with a resource reservoir below precipice may be "so devastating as to produce ultimate consequences (e.g., suicide, divorce, group dissolution)" [4] (pp. 144-145). For instance, employees with chronic work overload may commit suicide such as the workers at Foxconn in China, which is notoriously known for the consecutive suicides of employees despite being given free food and lodging, and extensive recreational facilities [7].

This study empirically tackles the corollary of resource loss spiral and the corollary of resource loss cycle on job demands and wellbeing to enhance the sustainability of service employees in workplaces. By preventing a resource loss spiral and resource loss cycle, the wellbeing and sustainability of an employee can be enhanced. Based on the basic relationships between quantitative and qualitative job demands, and wellbeing (e.g., [6,8,9]), this study examines the corollary of resource loss spiral, which is the synergistic negative influence of different types of job demands such as quantitative role overload and surface acting on job-related affective wellbeing (JAW). This study also examines the corollary of the resource loss cycle, which is the buffering role of one's resource reservoir to lessen the negative effects of job demands on JAW, through introducing one's cynicism as a state where one's energy resource was lost. This study examines that the negative relationships between job demands and JAW are amplified when cynicism is high $[3,8]$.

\section{Theory and Hypotheses}

Resource models assume that an individual has resource reservoirs, and that they have two important characteristics implicitly posited [1]. First, a resource reservoir has a lower limit that is referred to as the "critical survival level (p. 131)" [4] or "precipice (p. 318)" [1,5]. If a resource reservoir has resources below the critical survival level, then the individual with the resource reservoir would experience negative serious outcomes such as burnout, health problems, and absenteeism $[6,8,9]$. Furthermore, it could be "so devastating as to produce ultimate consequences (e.g., suicide, divorce, group dissolution)" [4] (pp. 144-145). These irreversible or functionally irreversible conditions may be presented to the individual and may undermine their sustainability. It can be metaphorically referred to as the bankruptcy of a firm. If a firm has no cash to pay for bills, it becomes bankrupt, and its management would be changed and would lose almost all rights for the firm.

Second, a resource reservoir has a threshold which can be called as overqualified level. If a resource reservoir has resources above the overqualified level, then an individual with the resource reservoir would have invested uselessly. Although this person may invest energy or effort into gaining resources above the overqualified level, the additionally acquired resource has almost no value as there is already sufficient resource to cope with stressful challenges [1] (p. 316). It is metaphorically referred to as a situation where a firm with excellent credit does not want to obtain a loan from a bank despite the banks providing an almost zero interest rate. 
COR theory assumes that resource loss has stronger impacts on an individual's stress resistance and wellbeing than resource gain $[4,5]$ as it might increase the likelihood that an individual is in a state of irreversible ultimate consequences. Wells et al. [3] added that the resource loss cycle "intensifies in momentum as each loss makes the system more vulnerable and less likely to meet ongoing demands of stress or day-to-day adaptation (p. 1173)". Van Woerkom et al. [6] clarified the meaning of resource loss spiral which is the synergistic influence of different types of job demand on negative serious outcomes.

Job demands refer to "those physical, psychological, social, or organizational aspects of the job that require sustained physical and/or psychological (cognitive and emotional) effort and are therefore associated with certain physiological and/or psychological costs (p. 86)" [10]. Examples are high work pressure, quantitative role overload, surface acting, and poor environmental conditions [10-13]. Previous studies have robustly shown that job demands are positively associated with negative outcomes such as burnout, health problems and absenteeism, and that they are also negatively associated with positive outcomes such as work engagement and wellbeing $[6,9,10,14,15]$.

Quantitative role overload, which can be the quantitative nature of job demands, is defined as "the individual's perception that the work cannot be done in the allotted time (p. 631)" due to the amount of work $[11,16]$. Prior studies on broadly defined workloads have rarely tackled the contingent factors such as other kinds of job demand and the individual's state of energy resources, which moderate the relationship between workload and wellbeing [6]. Van Woerkom et al. [6] dealt with emotional demands as contingent job demands of the relationship, which is a rare exception.

Surface acting, which can be a qualitative nature of job demands, is defined as the mental burden or conflict that an individual feels when they perform emotional labor to do tasks [12,13]. Prior studies on broadly defined emotion work have tackled the contingent factors such as other kinds of job demand and the individual's job resources, which moderate the relationship between emotion work and wellbeing [17]. Zapf et al. [18] empirically found that emotional exhaustion was predicted by interaction terms between job stressors such as time pressure, organizational problems, and the uncertainty of goal attainment on the one hand, and emotional dissonance on the other hand. Abraham [19] empirically showed that the negative relationship of emotional dissonance and job satisfaction appeared only when social support was low. However, the individual's state of energy resources has not been previously examined as a contingent factor in related empirical studies.

Job-related affective wellbeing (JAW) can be defined as one's experienced affect at work and has unique advantageous characteristics as a wellbeing variable. It is a pure measure of affect, rather than an attitudinal measure such as job satisfaction. It refers to job-specific affective response, rather than general affective responses such as PANAS (positive and negative affectivity scale). It also consists of high-arousal and low-arousal affects, whereas other measures such as PANAS and job satisfaction only focus on the high-arousal affect or low-arousal affect [20].

Van Woerkom et al. [6] also concluded that, although job demands-resources model research has examined the independent effects of various job demands on the psychological outcomes, the interaction effect between different types of job demands has never been studied. This has been viewed as a significant oversight in this field, especially given that COR theory also suggests that the resource losses caused from high demands in one aspect of a job might lead to a weakening of a resource reservoir to cope with another type of job demand, which triggers a resource loss spiral [21].

These two theoretical approaches commonly suggest that "the concurrent accumulation of demands increases the chances that a specific stressor will lead to negative outcomes (p. 142)" [6]. When an individual utilizes some of the resources from their resource reservoirs to cope with one type of job demand, they may be left with fewer resources in their resource reservoir to cope with other types of job demand. Therefore, this leads to more negative psychological outcomes. Van Woerkom et al. [6] specifically showed the positive interaction effect of workload and emotional demand on one's absenteeism. Their job demands variables were very similar to those of this study where workload was identical to quantitative role overload and emotional demand was the same as surface acting. 
Based on the rationale and the result, this study hypothesized that there is an exacerbating effect of the simultaneous experience of multiple job demands such as quantitative role overload and surface acting on JAW.

Hypothesis 1. Quantitative role overload (QRO) will negatively moderate the negative relationship between surface acting ( $S A$ ) and job-related affective wellbeing (JAW).

Hobfoll [1] suggested that, in the resource loss cycle, resource loss tended to lead to further resource loss with increased strength and speed as resources are the essential elements of people's stress resistance and wellbeing sustaining armamentarium. Resource loss creates the increased vulnerability of a resource reservoir because it necessarily uses resources to offset resource loss. Accordingly, an individual who has depleted resources is at a disadvantage when subsequent resource loss is required [22]. This creates a resource loss cycle that "intensifies in momentum as each loss makes the system more vulnerable and less likely to meet ongoing demands of stress or day-to-day adaptation (p. 1173)" [3].

In other words, the level of resource reservoir moderates the negative relationships between job demands and positive psychological outcomes such as JAW. Job demands reduce JAW more strongly when an individual has low levels of previous resource reservoir than when they have high levels of previous resource reservoir. Since an individual has a more vulnerable system when their resource reservoir is lower, they need more resources to cope with the next round of stress challenges.

Hobfoll and Lilly [4] predicted that those who lack resources take a defensive posture to guard their resources, since guarding resources ensures that minimal resource reservoir will be available. For instances, battered women who lack resources use passive coping. It has often been misunderstood as support for the women's masochistic tendencies [23]. Lazarus and Folkman's [24] transaction stress model explained that whether external challenges are threatening, and which coping mode is proper are determined by the level of one's resource reservoir.

Cynicism has been introduced as a state where one's energy resource has been lost. Cynicism is a dimension of MBI-GS (Maslach burnout inventory-general survey) and can be defined as "indifference or a distant attitude towards work in general, not necessarily with other people (p. 294)" [8,9]. Maslach and Leiter [25] presented conceptual models of burnout and the sequential stages where cynicism was seen as a consequence of exhaustion. As an individual loses their energy resources, he or she experiences exhaustion followed by cynicism.

Hockey's [26] state regulation model of compensatory control suggested two options to cope with very high perceived demands and the transition from one option to another option. The first option is the strain coping mode where the maximum effort budget is used to accommodate high demand. In this mode, target performance is maintained at the expense of increased compensatory costs such as negative psychological outcomes. The second is the passive coping mode, where the target performance is downward adjusted and the maximum effort budget is left, for instance, reducing levels of accuracy and speed, which means cynicism from the pursuit of task goals. Hockey's model described the burnout process as the transition from the strain coping mode to passive coping mode when the level of one's resource reservoir becomes low $[9,26]$. In sum, as the level of one's resource reservoir becomes low, the individual changes their coping mode from strain coping mode to passive coping mode. Therefore, their burnout stage changes from exhaustion to cynicism.

Since high cynicism means that an individual's energy resource is low, this study hypothesized that there are negative moderating effects of cynicism on the negative relationships between job demands such as quantitative role overload and surface acting, and JAW.

Hypothesis 2. Cynicism will negatively moderate the negative relationship between quantitative role overload (QRO) and job-related affective wellbeing (JAW). 
Hypothesis 3. Cynicism will negatively moderate the negative relationship between surface acting (SA) and job-related affective wellbeing (JAW).

\section{Method}

This study collected questionnaires from 299 employees in the Chinese banking industry through online and offline surveys during 15 April-6 June 2015. Hair et al. [27] recommended some guidelines for sample size. The desired sample size is approximately 20 observations for each independent variable to have the generalizability of the research results. Therefore, the sample size of this study could be as high as 260 as it has 13 independent variables. Since very large samples of 1000 observations or more make statistical significance tests overly sensitive, this study chose 300 as the sample size of this study. A Chinese banker, who has worked for the Industrial and Commercial Bank of China for a long time, collected 100 questionnaires from an offline paper and pencil survey using his personal relationships in the Chinese banking industry, which were completed by employees in banks such as the Industrial and Commercial Bank of China, Bank of China, and China Construction Bank. The remaining 199 questionnaires were collected from an online survey by a Chinese survey company named Wenjuan and came from various banks including the three banks listed above as well as the Bank of Communications and others.

Table 1 shows the characteristics of the Chinese bankers sampled. The sample consisted of 145 males and 154 females (52\%) where the respondents were usually aged in their 20s (61\%) and 30s $(37 \%)$. Most had bachelor's degrees $(80 \%)$ and held a management position $(86 \%)$. About a tenth $(11 \%)$ of the bankers had irregular job positions. Almost a third (37\%) had experienced turnover one or more times. The banks employing them included the Bank of China (17\%), Bank of Communications (25\%), Industrial and Commercial Bank of China (23\%), China Construction Bank (22\%), etc.

Table 1. Characteristics of the Chinese bankers sampled.

\begin{tabular}{|c|c|c|c|c|c|c|c|}
\hline \multicolumn{2}{|c|}{ Classification } & \multirow{3}{*}{$\begin{array}{r}\text { Cases } \\
145 \\
154 \\
\end{array}$} & \multirow{3}{*}{$\begin{array}{r}\text { Ratio } \\
48 \% \\
52 \%\end{array}$} & \multicolumn{2}{|r|}{ Classification } & \multirow{3}{*}{$\begin{array}{r}\text { Cases } \\
266 \\
33\end{array}$} & \multirow{3}{*}{$\begin{array}{r}\text { Ratio } \\
89 \% \\
11 \%\end{array}$} \\
\hline Gender & Male & & & \multirow{2}{*}{ Irregularity } & Regular & & \\
\hline & Female & & & & Irregular & & \\
\hline \multirow[t]{3}{*}{ Age } & $20 \mathrm{~s}$ & 182 & $61 \%$ & \multirow{5}{*}{$\begin{array}{l}\text { Tenure on } \\
\text { the bank }\end{array}$} & $<2$ years & 79 & $26 \%$ \\
\hline & $30 \mathrm{~s}$ & 111 & $37 \%$ & & $2-5$ years & 116 & $39 \%$ \\
\hline & $\geq 40$ & 6 & $2 \%$ & & $5-10$ years & 67 & $22 \%$ \\
\hline \multirow[t]{4}{*}{ Education } & High school & 18 & $6 \%$ & & 10-20 years & 16 & $5 \%$ \\
\hline & College & 238 & $80 \%$ & & $>20$ years & 21 & $7 \%$ \\
\hline & Master's degree & 31 & $10 \%$ & \multirow{2}{*}{$\begin{array}{l}\text { Turnover } \\
\text { experience }\end{array}$} & $\mathrm{No}$ & 189 & $63 \%$ \\
\hline & Doctor degree & 12 & $4 \%$ & & Yes & 110 & $37 \%$ \\
\hline \multirow[t]{5}{*}{ Position } & Clerk & 15 & $5 \%$ & \multirow{5}{*}{$\begin{array}{l}\text { Occupying } \\
\text { bank }\end{array}$} & Bank of China & 51 & $17 \%$ \\
\hline & Manager & 257 & $86 \%$ & & Bank of Communications & 74 & $25 \%$ \\
\hline & $\begin{array}{l}\text { Department } \\
\text { manager }\end{array}$ & 25 & $8 \%$ & & $\begin{array}{c}\text { Industrial and Commercial } \\
\text { Bank of China }\end{array}$ & 68 & $23 \%$ \\
\hline & Executive manager & 2 & $1 \%$ & & China Construction Bank & 66 & $22 \%$ \\
\hline & Total & 299 & $100 \%$ & & Other banks & 40 & $13 \%$ \\
\hline
\end{tabular}

Job-related affective wellbeing (JAW) was measured using the scale developed by Van Katwyk, Fox, Sector, and Kelloway [20], which consisted of the positive and negative job-related affects the respondent had experienced during the latest month. This study selected six items for positive affect including "My job made me feel at ease" and "My job made me feel satisfied", and six items for negative affect including "My job made me feel depressed" and "My job made me feel fatigued". All answers for the variables were provided on a 5-point Likert scale. The internal consistency of each subscale was good as the Cronbach's $\alpha$ for positive affect was 0.82 and that for negative affect was 
0.96. However, one item of positive affect was excluded by an exploratory factor analysis since it was improperly loaded to negative affect, which was "My job made me feel ecstatic". The Cronbach's $\alpha$ for the remaining five items increased to 0.92 . Convergent and discriminant validity were supported by the exploratory factor analysis except for improper loading. JAW was calculated as the value of positive affect by subtracting the value of the negative affect. Higher JAW meant a positive effect.

Quantitative role overload (QRO) was measured with three items from a scale developed by Ivancevich and Matteson [28] including "I am not given enough time to do what is expected of me in my job" and "It often seems like I have too much work for one person to do". The internal consistency of the scale was good $(\alpha=0.88)$. Higher quantitative role overload means that there is much work to do. Surface acting (SA) was measured with four items from a scale conceptualized by Hochschild [29] and developed by Brotheridge and Grandley [12] including "I pretend to have emotions that I don't really have" and "I hide my true feelings about a situation". The internal consistency of the scale was good $(\alpha=0.85)$. Higher surface acting means mental burdens or conflicts. An exploratory factor analysis supported the convergent and discriminant validity of these job demand variables.

Cynicism was measured with four items from a disengagement scale developed by Demerouti et al. [8] including "I get less and less engaged in my work" and "I don't feel challenging from my work". The internal consistency of the scale was good $(\alpha=0.89)$. Higher cynicism means indifference or a distant attitude toward work.

Some items were included for the control variables such as female, irregularity, position, turnover experience, and represented as dummy variables of the employing banks. Female is a dummy variable of the respondent's gender, which represents female when it is 1 . Irregularity is a dummy variable of the respondent's status in the bank, which represents an irregular worker when it is 1 . Position represents seven levels of job position in the bank. Turnover experience is a dummy variable of the respondent's experience, which means that they have previously experienced turnovers when the value is 1 .

A check of the common method variance issue was required as this study measured the independent, dependent, and moderating variables from a single respondent. According to Harman's single factor test, this study did an exploratory factor analysis including all research variables and concluded that the common method variance issue was not severe since the most explaining factor accounted for only $41.7 \%$ of the total variance among all the research variables, and therefore a single or general factor did not emerge [30].

\section{Results}

Table 2 shows the means, standard deviations, minimum, maximum, and Pearson correlations among the research variables. Correlations were as expected with all job demands and cynicism being negatively correlated with JAW. There were only modest correlations among the variables, which were input as regressors in the regression models, except for a correlation between surface acting and cynicism $(r=0.68)$. Further regression models did not have any problems with multicollinearity indices such as variance inflation factor, tolerance, eigenvalue, and condition index [27].

This study conducted ordinary least square regressions using SPSS 24.0 such that three relevant moderation effects were examined, as shown in Models 1-5 in Table 3. Model 1 contained only control variables. In Model 2, two job demand variables were added. In Model 3, the interaction term of quantitative role overload and surface acting was included to test Hypothesis 1 . This study mean-centered these variables before multiplying them [31]. Model 4 contained control variables, two job demands, and cynicism. In Model 5, the interaction terms of quantitative role overload and cynicism, and surface acting and cynicism were added to test Hypotheses 2 and 3 . This study also mean-centered these variables before multiplying them [31]. Since the interaction terms had high correlations with other interaction terms despite using the multiplications of the mean-centered variables, this study separated Model 3 to test Hypothesis 1 and Model 5 to test Hypotheses 2 and 3. 
Table 2. Means, standard deviations (S.D.), minimum (Min), maximum (Max), and correlations among variables.

\begin{tabular}{|c|c|c|c|c|c|c|c|c|c|c|c|c|c|c|c|}
\hline Variable & Mean & S.D. & Min & Max & 1 & 2 & 3 & 4 & 5 & 6 & 7 & 8 & 9 & 10 & 11 \\
\hline 1. Job-related affective wellbeing & 0.61 & 1.39 & -4 & 4 & $(0.92)$ & & & & & & & & & & \\
\hline 2. Quantitative role overload & 2.62 & 1.02 & 1 & 5 & $-0.17^{* *}$ & $(0.88)$ & & & & & & & & & \\
\hline 3. Surface acting & 2.93 & 0.89 & 1 & 5 & $-0.48^{* *}$ & $0.33 * *$ & $(0.85)$ & & & & & & & & \\
\hline 4. Cynicism & 2.40 & 0.89 & 1 & 5 & $-0.59^{* *}$ & $0.33 * *$ & $0.68^{* *}$ & $(0.89)$ & & & & & & & \\
\hline 5. Female (d) & 0.52 & 0.50 & 0 & 1 & -0.04 & $0.14^{*}$ & 0.03 & 0.02 & - & & & & & & \\
\hline 6. Irregularity (d) & 0.11 & 0.31 & 0 & 1 & $-0.18^{* *}$ & -0.01 & $0.18^{* *}$ & $0.18^{* *}$ & $0.15^{* *}$ & - & & & & & \\
\hline 7. Job position & 2.54 & 1.09 & 1 & 7 & 0.11 & -0.07 & $-0.20^{* *}$ & $-0.19^{* *}$ & $-0.17^{* *}$ & $-0.26^{* *}$ & - & & & & \\
\hline 8. Turnover experience $(\mathrm{d})$ & 0.37 & 0.48 & 0 & 1 & $-0.16^{* *}$ & 0.09 & $0.14^{* *}$ & $0.14^{*}$ & -0.02 & 0.06 & 0.06 & - & & & \\
\hline 9. Bank of China (d) & 0.17 & 0.38 & 0 & 1 & -0.01 & -0.04 & $-0.13 * *$ & -0.06 & -0.02 & -0.10 & $0.16 * *$ & -0.05 & - & & \\
\hline 10. Bank of Communications (d) & 0.25 & 0.43 & 0 & 1 & 0.02 & -0.06 & -0.02 & -0.07 & 0.11 & -0.03 & -0.11 & -0.05 & $-0.26^{* *}$ & - & \\
\hline $\begin{array}{l}\text { 11. Industrial and Commercial } \\
\text { Bank of China (d) }\end{array}$ & 0.23 & 0.42 & 0 & 1 & 0.05 & 0.07 & 0.03 & 0.06 & -0.06 & 0.06 & 0.07 & -0.08 & $-0.25^{* *}$ & $-0.31^{* *}$ & - \\
\hline 12. China Construction Bank (d) & 0.22 & 0.42 & 0 & 1 & -0.02 & 0.06 & 0.06 & 0.06 & 0.03 & -0.03 & -0.01 & 0.10 & $-0.24^{* *}$ & $-0.31 * *$ & $-0.29 *$ \\
\hline
\end{tabular}

Note: $N=299$; (d) indicates a dummy variable; Cronbach's $\alpha$ in parentheses on diagonals; ${ }^{*}$ correlation significant $(p<0.05)$; ${ }^{* *}$ correlation significant $(p<0.01)$. 
Table 3. Regression results on job-related affective wellbeing (JAW).

\begin{tabular}{|c|c|c|c|c|c|c|c|c|c|c|}
\hline \multirow{3}{*}{ Control variables } & \multicolumn{10}{|c|}{ Job-Related Affective Wellbeing (JAW) } \\
\hline & \multicolumn{2}{|c|}{ Model 1} & \multicolumn{2}{|c|}{ Model 2} & \multicolumn{2}{|c|}{ Model 3} & \multicolumn{2}{|c|}{ Model 4} & \multicolumn{2}{|c|}{ Model 5} \\
\hline & & & & & & & & & & \\
\hline \multirow[t]{2}{*}{ Intercept } & 0.53 & + & 2.89 & $* * *$ & 2.78 & $* * *$ & 3.11 & $* * *$ & 3.19 & $* * *$ \\
\hline & $(0.31)$ & & $(0.40)$ & & $(0.39)$ & & $(0.36)$ & & $(0.38)$ & \\
\hline \multirow[t]{2}{*}{ Female $(d)$} & -0.03 & & -0.03 & & -0.07 & & -0.08 & & -0.10 & \\
\hline & $(0.16)$ & & $(0.15)$ & & $(0.15)$ & & $(0.14)$ & & $(0.14)$ & \\
\hline \multirow[t]{2}{*}{ Irregularity $(\mathrm{d})$} & -0.67 & * & -0.44 & + & -0.41 & + & -0.29 & & -0.29 & \\
\hline & $(0.27)$ & & $(0.24)$ & & $(0.24)$ & & $(0.22)$ & & $(0.22)$ & \\
\hline \multirow[t]{2}{*}{ Job position } & 0.11 & & 0.00 & & 0.05 & & -0.04 & & -0.02 & \\
\hline & $(0.08)$ & & $(0.07)$ & & $(0.07)$ & & $(0.07)$ & & $(0.07)$ & \\
\hline \multirow[t]{2}{*}{ Turnover experience $(\mathrm{d})$} & -0.43 & * & -0.24 & & -0.28 & + & -0.17 & & -0.19 & \\
\hline & $(0.17)$ & & $(0.15)$ & & $(0.15)$ & & $(0.14)$ & & $(0.14)$ & \\
\hline \multirow[t]{2}{*}{ Bank of China (d) } & -0.09 & & -0.24 & & -0.09 & & -0.07 & & -0.07 & \\
\hline & $(0.30)$ & & $(0.27)$ & & $(0.27)$ & & $(0.25)$ & & $(0.25)$ & \\
\hline Bank of & 0.11 & & 0.04 & & 0.05 & & 0.09 & & 0.09 & \\
\hline Communications (d) & $(0.27)$ & & $(0.24)$ & & $(0.24)$ & & $(0.22)$ & & $(0.23)$ & \\
\hline Industrial \& Commercial & 0.16 & & 0.19 & & 0.15 & & 0.34 & & 0.33 & \\
\hline Bank of China (d) & $(0.28)$ & & $(0.25)$ & & $(0.25)$ & & $(0.23)$ & & $(0.23)$ & \\
\hline China Construction & 0.03 & & 0.06 & & 0.06 & & 0.18 & & 0.16 & \\
\hline Bank (d) & $(0.28)$ & & $(0.25)$ & & $(0.25)$ & & $(0.23)$ & & $(0.23)$ & \\
\hline \multicolumn{11}{|l|}{ Study variables } \\
\hline \multirow{2}{*}{\multicolumn{3}{|c|}{$\begin{array}{l}\text { Quantitative role overload } \\
(\mathrm{QRO})\end{array}$}} & -0.02 & & 0.02 & & 0.06 & & 0.06 & \\
\hline & & & $(0.08)$ & & & & $(0.07)$ & & $(0.07)$ & \\
\hline Surface acting (SA) & & & -0.72 & $* * *$ & -0.74 & $* * *$ & -0.25 & * & -0.29 & $* *$ \\
\hline \multirow[t]{2}{*}{$\mathrm{QRO} \times \mathrm{SA}$} & & & & & $\begin{array}{l}(0.09) \\
-0.20\end{array}$ & ** & & & & \\
\hline & & & & & $(0.08)$ & & & & & \\
\hline \multirow[t]{2}{*}{ Cynicism (C) } & & & & & & & -0.77 & $* * *$ & -0.73 & $* * *$ \\
\hline & & & & & & & $(0.10)$ & & $(0.11)$ & \\
\hline \multirow[t]{2}{*}{$\mathrm{QRO} \times \mathrm{C}$} & & & & & & & & & 0.11 & \\
\hline & & & & & & & & & $(0.08)$ & \\
\hline \multirow{2}{*}{$\mathrm{SA} \times \mathrm{C}$} & & & & & & & & & -0.16 & + \\
\hline & & & & & & & & & $(0.10)$ & \\
\hline$R^{2}$ & 0.062 & & 0.259 & & 0.277 & & 0.380 & & 0.387 & \\
\hline Adj. $R^{2}$ & 0.037 & & 0.234 & & 0.249 & & 0.356 & & 0.359 & \\
\hline$F$-value & 2.4 & * & 10.1 & $* * *$ & 10.0 & $* * *$ & 16.0 & $* * *$ & 13.8 & $* * *$ \\
\hline
\end{tabular}

Note: (d) indicates a dummy variable; standard errors in parentheses; ${ }^{+} p<0.1 ;^{*} p<0.05$; $^{* *} p<0.01$; $^{* * *} p<0.001$.

Table 3 presents the results of the hierarchical regression analyses which were conducted to test the hypotheses. As can be seen in Model 3, surface acting had a negative relationship with JAW ( $B=-0.74$, $p<0.001$ ), but quantitative role overload had no relationship with JAW ( $\mathrm{B}=0.02$, not significant). These results indicate that surface acting lessened JAW, but quantitative role overload had no impact on JAW. The interaction term for quantitative role overload and surface acting was negatively related to JAW $(B=-0.20, p<0.01)$. Figure 1a shows two simple slopes, which represent the relationships between surface acting and JAW when the quantitative role overload is low and when it is high. These confirmed Hypothesis 1, as the high level of quantitative role overload amplified the negative relationship between surface acting and JAW.

As can be seen in Model 5, the interaction term for quantitative role overload and cynicism was not significantly related to JAW ( $\mathrm{B}=0.11$, not significant). This did not confirm Hypothesis 2 , as the high level of cynicism did not amplify the negative relationship between quantitative role overload and JAW.

The interaction term for surface acting and cynicism was negatively related to JAW $(B=-0.16$, $p<0.1)$. Figure $1 \mathrm{~b}$ shows two simple slopes, which represent the relationships between surface acting and JAW when cynicism is low and high. These results confirmed Hypothesis 3, as the high level of cynicism amplified the negative relationship between surface acting and JAW. 


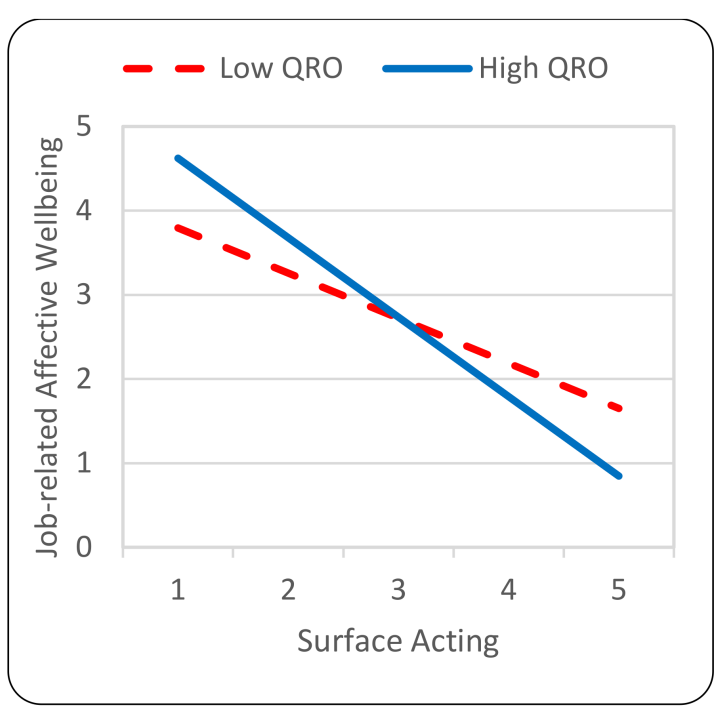

(a)

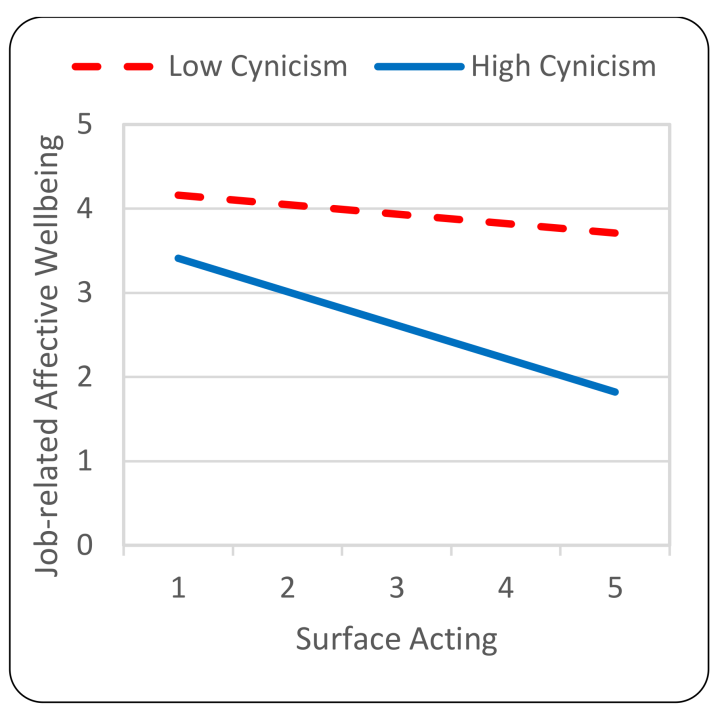

(b)

Figure 1. (a) Plot of the synergistic negative effect of quantitative role overload (QRO) and surface acting (SA) on job-related affective wellbeing (JAW); and (b) plot of the moderating effect of cynicism (C) on the relationship between surface acting (SA) and JAW.

\section{Discussion}

The results of this study were as follows: (1) surface acting had a negative relationship with JAW, but quantitative role overload had no relationship with JAW; (2) quantitative role overload negatively moderated the negative relationship between surface acting and JAW, confirming Hypothesis 1 (Figure 1a); and (3) cynicism negatively moderated the negative relationship between surface acting and JAW, confirming Hypothesis 3 (Figure 1b), but did not have any moderating effect on the relationship between quantitative role overload and JAW related to Hypothesis 2.

The first result concerning the main effects of job demands implied that quantitative role overload was a minor issue for the employee, but surface acting was a critical issue in the employee's wellbeing in the context of the Chinese banking industry. Even if an employee had a lot of work to do under time pressure, it did not have a direct effect on their wellbeing. Even if the employee had a little surface acting, it did matter to the employee's wellbeing. Prior studies have robustly shown that job demands are positively associated with negative outcomes such as burnout, health problems and absenteeism, and that they are also negatively associated with positive outcomes such as work engagement and wellbeing $[6,9,10,14,15]$. However, this study showed that job demands could have a different impact on one's wellbeing according to the type of job demand. Furthermore, this study speculated that a qualitative job demand such as surface acting might have a stronger effect on one's wellbeing than a quantitative job demand such as quantitative role overload. Some prior studies have classified job demands as hindrance and challenge stressors. Challenge stressors potentially promote the personal growth and achievement of the employee, and therefore enhance wellbeing [32].

Therefore, managers must be very cautious when disseminating work related to surface acting to their employees to ensure a sustainable workforce in the Chinese banking industry. Relatively, they can have various possibilities to disseminate quantitative job demands or to give time pressure on their employees since they had no negative effect on JAW.

The second result, as shown in Figure 1a and related to Hypothesis 1, implies that experiencing various simultaneous job demands had a negatively exacerbating effect on JAW, which confirmed Van Woerkom and coworkers' [6] resource loss spiral argument. Quantitative role overload negatively moderated the negative relationship between surface acting and JAW. This was also consistent with role conflict theory [33], and with resource loss spiral, which means that resource loss, caused by 
handling one type of job demand, lessens an employee's ability to cope with another type of job demand. Prior literature regarding the job demands-resources model has usually been interested in the main effects of various job demands on psychological outcomes, and in the moderating effects of job resources on the relationships between job demands and psychological outcomes. However, focus has not been placed in the interaction effect or the synergistic effect among the types of job demands on one's wellbeing, with the exception of Van Woerkom et al. [6].

This result has implications for managers on how to design the configurations of job demands in the Chinese banking industry. Managers must also be very cautious to disseminate quantitative job demands or to give time pressure on their employees to ensure a sustainable workforce if they have suffered from surface acting. Managers could have various possibilities to disseminate quantitative job demands or to give time pressure on their employees if they have low levels of surface acting, since quantitative role overload may be a challenge stressor, which can enhance the employee's wellbeing [32].

The third result, as shown in Figure $1 \mathrm{~b}$ and related to Hypothesis 3, implies the buffering role of one's energy resource to lessen the negative effects of job demands on JAW. There exists a vicious circle, known as the resource loss cycle, where surface acting reduces JAW more strongly when an individual has low levels of previous energy resources than when they have high levels of previous energy resources. In other words, surface acting reduces JAW more strongly when an individual has high cynicism than it reduces JAW when they have low cynicism.

The result has implications for managers on how to handle service employees according to their levels of cynicism or energy resources in the Chinese banking industry. Managers must also be very cautious when disseminating surface acting work to their employees to ensure a sustainable workforce if they have high levels of cynicism or low levels of energy resources. This means that managers must be careful when employees show symptoms of cynicism, for instance, "they don't feel challenging from their work" [8].

This study makes several contributions. First, this study empirically tackled the corollary of resource loss spiral and the corollary of resource loss cycle on job demands and wellbeing. Resource loss spiral means the synergistic negative influence of different types of job demand on wellbeing [6]. Resource loss cycle "intensifies in momentum as each loss makes the system more vulnerable and less likely to meet ongoing demands of stress or day-to-day adaptation (p. 1173)" [3].

Second, this study addressed the sustainability issue of service employees in the workplace. This study has implications for how to design the configurations of job demands, and how to handle service employees with low levels of their energy resources [34,35].

Third, this study extended research on the COR theory and the job demands-resources model by making the wellbeing of an individual a dependent variable, which studies on resiliency, positive psychology, and positive organizational behavior have dealt with [1,9].

Fourth, this study examined quantitative role overload and cynicism as contingent factors that moderate the relationship between emotion work and wellbeing. Prior studies on broadly defined emotion work have tackled contingent factors such as other kinds of job demand and job resources, which moderate the relationship between emotion work and wellbeing [17].

This study had many limitations. First, this study had a cross-sectional design, even though main concepts such as resource loss spiral and resource loss cycle are dynamic concepts, which are processes over time. Furthermore, this study examined the corollary of these concepts, rather than the concepts themselves. It was also proper to interpret the results of this study as associations among variables, rather than causal relationships among variables. Therefore, future research needs to have a longitudinal research design.

Second, this study had limited external validities since this study only collected data from employees in the Chinese banking industry. Foxconn in China is a unique case with consecutive suicides of employees. Since Chinese banks may have unique cultural characteristics, future studies from different industries and different nations are required. 
Despite these limitations, this study provides two suggestions for service employees. First, in the case of employees with high cynicism or low energy resources, managers should avoid giving them surface acting work since surface acting amplifies the negative effect on wellbeing when cynicism is high. Managers should give them quantitative job demands, since quantitative role overload may be a challenge stressor, which can enhance an employee's wellbeing [32]. Even if employees have high cynicism, they can still perform their quantitative job demands sustainably.

Second, in the case of employees with low cynicism or high energy resources, managers could provide them with surface acting work. In this case, it is better to avoid assigning quantitative job demands additionally, since simultaneously experiencing various job demands has a negatively exacerbating effect on JAW. If they are not given many quantitative job demands, again they can still perform their surface acting work sustainably.

Acknowledgments: This research was financially supported by Hansung University. The author especially thanks $\mathrm{Xu}$ Yang for helping to collect the data for this study. I would like to thank three anonymous reviewers for their helpful comments and suggestions on the manuscript.

Author Contributions: The author conceived and designed this study, conducted all analyses, and wrote the paper.

Conflicts of Interest: The author declares no conflict of interest. The founding sponsor had no role in the design of the study; in the collection, analyses, or interpretation of data; in the writing of the manuscript, and in the decision to publish the results.

\section{References}

1. Hobfoll, S.E. Social and psychological resources and adaptation. Rev. Gen. Psychol. 2002, 6, 307-324. [CrossRef]

2. Diener, E.; Fujita, F. Resources, personal strivings, and subjective wellbeing: A nomothetic and idiographic approach. J. Personal. Soc. Psychol. 1995, 68, 926-935. [CrossRef]

3. Wells, J.D.; Hobfoll, S.E.; Lavin, J. When it rains, it pours: The greater impact of resource loss compared to gain on psychological distress. Personal. Soc. Psychol. Bull. 1999, 25, 1172-1182. [CrossRef]

4. Hobfoll, S.E.; Lilly, R.S. Resource conservation as a strategy for community psychology. J. Commun. Psychol. 1993, 21, 128-148. [CrossRef]

5. Hobfoll, S.E.; Shoham, S.B.; Ritter, C. Women's satisfaction with social support and their receipt of aid. J. Personal. Soc. Psychol. 1991, 61, 332-341. [CrossRef]

6. Van Woerkom, M.; Bakker, A.B.; Nishii, L.H. Accumulative job demands and support for strength use: Fine-tuning the job demands-resources model using conservation of resource theory. J. Appl. Psychol. 2016, 101, 141-150. [CrossRef] [PubMed]

7. Economist. Suicides at Foxconn: Light and Death. Available online: https://www.economist.com/node/ 16231588 (accessed on 8 March 2018).

8. Demerouti, E.; Bakker, A.B.; Nachreiner, F.; Schaufeli, W.B. The job demands-resources model of burnout. J. Appl. Psychol. 2001, 86, 499-512. [CrossRef] [PubMed]

9. Schaufeli, W.B.; Bakker, A.B. Job demands, job resources, and their relationship with burnout and engagement: A multi-sample study. J. Organ. Behav. 2004, 25, 293-315. [CrossRef]

10. Bakker, A.B.; Demerouti, E.; Verbeke, W. Using the job demands-resources model to predict burnout and performance. Hum. Resour. Manag. 2004, 43, 83-104. [CrossRef]

11. Bolino, M.C.; Turnley, W.H. The personal costs of citizenship behavior: The relationship between individual initiative and role overload, job stress, and work-family conflict. J. Appl. Psychol. 2005, 90, 740-748. [CrossRef] [PubMed]

12. Brotheridge, C.M.; Grandey, A.A. Emotional labor and burnout: Comparing two perspectives of people work? J. Vocat. Behav. 2002, 60, 17-39. [CrossRef]

13. Morris, J.A.; Feldman, D.C. The dimensions, antecedents, and consequences of emotional labor. Acad. Manag. Rev. 1996, 21, 986-1010.

14. Hakanen, J.J; Schaufeli, W.B.; Ahola, K. The job demands-resources model: A three-year cross-lagged study of burnout, depression, commitment, and work engagement. Work Stress 2008, 22, 224-241. [CrossRef] 
15. De Lange, A.H.; Taris, T.W.; Kompier, M.A.; Houtman, I.L.D.; Bongers, P.M. The very best of millennium: Longitudinal research and the demand-control-(support) model. J. Occup. Health Psychol. 2003, 8, 282-305. [CrossRef] [PubMed]

16. Cordes, C.L.; Dougherty, T.W. A review and an integration of research on job burnout. Acad. Manag. Rev. 1993, 18, 621-656.

17. Zapf, D. Emotion work and psychological well-being: A review of the literature and some conceptual considerations. Hum. Resour. Manag. Rev. 2002, 12, 237-268. [CrossRef]

18. Zapf, D.; Seifert, C.; Schmutte, B.; Mertini, H.; Holz, M. Emotional work and job stressors and their effects on burnout. Psychol. Health 2001, 16, 527-545. [CrossRef] [PubMed]

19. Abraham, R. Emotional dissonance in organizations: Antecedents, consequences and moderators. Genet. Soc. Gen. Psychol. Monogr. 1998, 124, 229-246. [PubMed]

20. Van Katwyk, P.T.; Fox, S.; Spector, P.E.; Kelloway, E.K. Using the job-related affective well-being scale (JAWS) to investigate affective responses to work stressors. J. Occup. Health Psychol. 2000, 5, 219-230. [CrossRef] [PubMed]

21. Hobfoll, S.E. The influence of culture, community, and the nested-self in the stress process: Advancing conservation of resources theory. Appl. Psychol. Int. Rev. 2001, 50, 337-421. [CrossRef]

22. Lane, C.L.; Hobfoll, S.E. How loss affects anger and alienates potential supporters. J. Consult. Clin. Psychol. 1992, 60, 935-942. [CrossRef] [PubMed]

23. Hobfoll, S.E. Conservation of resources: A new attempt at conceptualizing stress. Am. Psychol. 1989, 44, 513-524. [CrossRef] [PubMed]

24. Lazarus, R.S.; Folkman, S. Stress, Appraisal, and Coping; Springer: New York, NY, USA, 1984.

25. Maslach, C.; Leiter, M.P. Understanding the burnout experience: Recent research and its implications for psychiatry. World Psychiatr. 2016, 15, 103-111. [CrossRef] [PubMed]

26. Hockey, G.J. Compensatory control in the regulation of human performance under stress and high workload: A cognitive-energetical framework. Biol. Psychol. 1997, 45, 73-93. [CrossRef]

27. Hair, J.E., Jr.; Anderson, R.E.; Tatham, R.L.; Black, W.C. Multivariate Data Analysis with Readings, 4th ed.; Prentice-Hall International, Inc.: Upper Saddle River, NJ, USA, 1995.

28. Ivancevich, J.M.; Matteson, M.T. Stress and Work: A Managerial Perspective; Scott, Foresman and Company: Glenview, IL, USA, 1980.

29. Hochschild, A.R. The Managed Heart: Commercialization and Human Feeling; University of California Press: Berkeley, CA, USA, 1983.

30. Podsakoff, P.M.; Organ, D.W. Self-reporters in organizational research: Problems and prospects. J. Manag. 1986, 12, 531-544.

31. Venkatraman, N. The concept of fit in strategy research: Toward verbal and statistical correspondence. Acad. Manag. Rev. 1989, 14, 423-444.

32. Demerouti, E.; Bakker, A. The job demands-resources model: Challenges for future research. SA J. Ind. Psychol. 2011, 37, 1-9. [CrossRef]

33. Kahn, R.L.; Wolfe, D.M.; Quinn, R.P.; Snoek, J.D.; Rosenthal, R.A. Organizational Stress: Studies in Role Conflict and Ambiguity; Wiley: Oxford, UK, 1964.

34. Jimenez, P.; Winkler, B.; Bregenzer, A. Developing sustainable workplaces with leadership: Feedback about organizational working conditions to support leaders in health-promoting behavior. Sustainability 2017, 9, 1944. [CrossRef]

35. Yeh, L. Incorporating workplace injury to measure the safety performance of industrial sectors in Taiwan. Sustainability 2017, 9, 2241. [CrossRef]

(C) 2018 by the author. Licensee MDPI, Basel, Switzerland. This article is an open access article distributed under the terms and conditions of the Creative Commons Attribution (CC BY) license (http:/ / creativecommons.org/licenses/by/4.0/). 